U.S. Department

of Transportation

National Highway

Traffic Safery

Administration

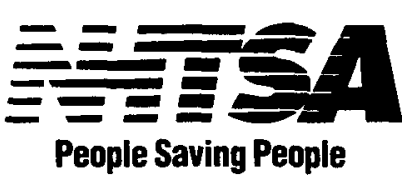

DOT HS 808417

June 1995

Final Report

\title{
Analysis of Driving Histories of ADHD Subjects
}




\begin{tabular}{|c|c|}
\hline $\begin{array}{l}\text { 1. Report No. } \\
\text { DOT HS } 808 \quad 417\end{array}$ & 3. Recipient's Catalog No. \\
\hline $\begin{array}{l}\text { 4. Title and Subtitle } \\
\text { Analysis of Driving Histories of ADHD Subjects }\end{array}$ & $\begin{array}{l}\text { 5. Report Date } \\
\text { June } 1995\end{array}$ \\
\hline & 6. Performing Organization Code \\
\hline $\begin{array}{l}\text { 7. Author(s) } \\
\text { Nadine M. Lambert }\end{array}$ & 8. Performing Organization Report No. \\
\hline $\begin{array}{l}\text { 9. Performing Organization Name and Address } \\
\text { School of Education }\end{array}$ & 10. Work Unit No. (TRAIS) \\
\hline $\begin{array}{l}\text { University of California at Berkeley } \\
\text { Berkeley, CA } 94720\end{array}$ & $\begin{array}{l}\text { 11. Contract or Grant No. } \\
\text { DTNH2 } 2-94-\mathrm{H}-05320 \\
\end{array}$ \\
\hline & 13. Type of Report and Period Covered \\
\hline $\begin{array}{l}\text { 12. Sponsoring Agency Name and Address } \\
\text { U.S. Department of Transportation } \\
\text { National Highway Traffic Safety Administration }\end{array}$ & Final Report \\
\hline $\begin{array}{l}400 \text { Seventh Street, S.W. } \\
\text { Washington, DC } 20590\end{array}$ & 14. Sponsoring Agency Code \\
\hline
\end{tabular}

15. Supplementary Notes

16. Abstract

The goals of this research were to assess the relationship between early childhood diagnosis of Attention Deficit Hyperactivity Disorder (ADHD) and later driving performance. Driving records were obtained for ADHD and comparison subjects who were participants in a prospective longitudinal study begun in 1974 to explore the identification, treatment, and life histories of hyperactive children. The subjects had been selected in 1974 from a representative sample of over 5,000 children in the school-age population of Alameda and Contra Costa Counties in California.

The analyses compared subjects diagnosed as having severe ADHD to all other subjects. The latter group included subjects with mild or moderate ADHD, plus subjects not diagnosed as having ADHD. Results showed the severe ADHD subjects more likely than the comparison group to have been convicted of the following moving violations: sign and signal, speeding, roadway marking, following too closely, and passing. For nonmoving violations, the percentage of convicted violators was significantly higher among the severe ADHDs in almost all categories (equipment, licensing, failure to appear in court, failure to pay fines, ignoring police authority). Statistically significant differences were not found between the severe ADHDs and the comparison group for most types of crashes. However, there again tended to be higher percentages among the severe ADHDs. Moreover, the only recorded crashes involving fatalities (2) occurred among the severe ADHDs.

\begin{tabular}{|l|l}
\hline 17. Key Words & 18. Distribution Statement
\end{tabular}

ADHD

Hyperactive

Longi tudinal

This document is available to the public from the National Technical Information

Database

Driving Records

19. Security Classif. (of this report)

Service, Springfield, Virginia 22161

Unclassified

20. Security Classif. (of this page)
Unclassified

21. No. of Pages

22. Price

Form DOT F $1700.7 \quad(8-72)$

Reproduction of completed page authorized 


\title{
U.S. DEPARTMENT OF TRANSPORTATION NATIONAL HIGHWAY TRAFFIC SAFETY ADMINISTRATION
}

\author{
COOPERATIVE AGREEMENT AWARD
}

Final Report - June 15, 1995

NHTSA COOPERATIVE AGREEMENT

PROJECT TITLE

GRANTEE
DTNH22 - $94-\mathrm{H}-05320$

Analysis of Driving Histories of ADHD subjects

Nadine M. Lambert University of California at Berkeley

\section{Goals}

The goals of this research were to assess the relationship between early childhood diagnosis of Attention Deficit Hyperactivity Disorder (ADHD) and later driving performance. To accomplish this objective, we analyzed the driving histories of a large group of $A D H D$ and comparison subjects who were born in the $60 \mathrm{~s}$.

The effort was part of a prospective longitudinal study begun in 1974 when the grantee began exploring the identification, treatment, and life histories of hyperactive children along with comparison groups. There were a total of 492 subjects in the study who were selected from a representative sample of over 5,000 children in the school-age population of Alameda and Contra Costa counties in California. Initially, 175 were diagnosed in childhood as hyperactive, 107 showed behavioral characteristics comparable to diagnosed ADHD subjects but had different medical interventions and treatment histories, and 51 had behavior problems in childhood without showing the symptoms of ADHD. The remaining 159 formed a comparison group who were enrolled in the same classrooms and were matched by age and gender to the ADHD sample.

The 492 subjects were followed through high school and then into adulthood with periodic data collection from interviews and ratings provided by the subjects, their parents, teachers and physicians. At the first adult data collection period extending from 1991 through 1994, we obtained driving histories from the California Department of Motor Vehicles and from out-of-state motor vehicle departments for 463 of 492 subjects.

The specific questions addressed in this study were:

1. Do driving histories of ADHD subjects classified as having severe symptoms differ from age mates by the time they reach age 26. 
2. Can any differences in driving histories between ADHD severe subjects and age mates be accounted for by access to vehicles as evidenced by: a) having a car registered in the subject's name, or b) by the length of time a subject had been driving, as evidenced by age at which the drivers license was first issued.

\section{Subjects}

Criteria for ADHD from 1968 through 1995

The current diagnostic nomenclature used by health professionals to assign a diagnosis to children referred for the symptoms of Attention Deficit Hyperactivity Disorder (ADHD) is specified in the Diagnostic and Statistical Manual, 4th edition, (DSMIV) (APA, 1994). The edition includes the fourth set of criteria for diagnosing ADHD that has been used since 1968, or during the period of the prospective longitudinal study of which this investigation is a part. With each DSM from DSMII (APA, 1968) through DSMIII (APA, 1980) and DSMIII-R (APA, 1987) the criteria for what constitutes $A D H D$ have changed. The current DSMIV presents criteria for two sets of symptoms, inattention and hyperactivity-impulsivity, which singly or in combination lead to a DSMIV diagnosis of ADHD.

One can assume that before a child reaches the physician's office for evaluation, there have been concerns about the presence of one or more of these types of ADHD symptoms at home or at school for a period of time; in other words, the child's behavior is characterized by symptoms of long-standing. Once the referral is made, the health professional uses the DSMIV to assess the extent to which the child can be considered to have "inattention" or to be "hyperactive-impulsive". If a child's behavior is characterized by both inattention and hyperactivity-impulsivity, he or she is considered to be $A D H D$-combined. Or if only one of the criteria is satisfied, the child can be judged to be ADHD Primarily Inattentive, or ADHD-Primarily Hyperactive-Impulsive. In addition to meeting these criteria, the DSMIV states that: a) some of the symptoms must have been present before age 7 , b) some impairment from the symptoms is present in at least two settings, c) there must be clear evidence of significant impairment in social, academic, or occupational functioning, and d) there are no competing diagnoses to explain the behavior.

For this investigation, we developed a set of proxies for the criteria established for a DSMIV diagnosis of ADHD, and extended some of the criteria to develop a measure of severity of the presenting symptoms using data that were available for all of the 492 subjects in our prospective study, including the 463 with driving histories. 
The objective was to identify a set of subjects who as children would have met all of the DSMIV criteria for diagnosing $A D H D$ if they were to be evaluated today and whose problems could be considered to be pervasive and severe. Using such a group of subjects with the most severe patterns of ADHD behavior, then, enabled us to compare their driving histories with another subject group that included all of the non-ADHD age mate subjects along with those who had situational and less serious ADHD symptoms.

Proxies for DSMIV classifications.

The decision rules used to approximate DSMIV ADHD diagnoses for our community sample of subjects are provided in detail in Appendix A. Abbreviated descriptions follow.

1. Preliminary selection of subjects with an overall pattern of ADHD problem behavior. The first step in this effort was to establish a method for selecting subjects whose behavior at home and/or school was characterized by problems of inattention, hyperactivity, and impulsivity. For this purpose we selected from the total sample subjects whose overall ADHD ratings on either or both the home and school versions of the Children's Attention and Adjustment Survey (CAAS) (Lambert, Sandoval \& Hartsough, 1990) were above one standard deviation from the mean on a norm reference sample. All of these subjects were then evaluated in the following ways.

2. Inattention and hyperactivity-impulsivity symptoms. Subjects were rated on "inattentive" and "hyperactive-impulsive" symptom patterns according to DSMIV standards, using scores derived from the CAAS Inattention scale and the combined CAAS Hyperactivity and Impulsivity scales. Both home and school forms were used.

3. Assignment of Levels of Severity to CAAS ADHD DSMIV Symptom Profiles. We extended DSMIV diagnostic requirements by establishing the level of severity of the symptoms. Each subject whose "inattentive" or "hyperactive-impulsive" ratings met the decision rules was then assigned a DSMIV ADHD severity rating as follows :

DSMIV ADHD Symptoms-Severe - - Both teacher and parent ratings were in the selection range (see Appendix A) for ADHD-combined, $\mathrm{ADHD}$-Primarily Inattentive, or ADHD-Primarily HyperactiveImpulsive.

DSMIV ADHD Symptoms-Moderate - Either the parent ratings or the teacher ratings were in the selection range on both the Inattentive and Hyperactive-Impulsive symptoms or there was a mixed pattern of ratings.

DSMIV ADHD Symptoms-Mild - Only one of the four scales (parent ratings of inattention or hyperactivity-impulsivity or teacher ratings of inattention or hyperactivity-impulsivity) was in the selection range. 
4. Onset of symptoms. Age of onset of the symptoms to meet the DSMIV criteria was determined by one of the following: a) a parent report that the symptoms first were noted before age 8 ; b) medical assistance for problems associated with hyperactivity were sought before age 8 ; or, c) parent rating of the child's temperament on "activity level " or "attention span and persistence" was at the extremes of the continuum of a representative sample of subjects (Lambert, 1982) using a parent interview fashioned from Thomas, Chess, and Birch's New York Longitudinal Study. (1968)

5. Impairment in functioning. criteria for impairment if a parent, teacher, and/or physician judged him or her to be experiencing ADHD symptoms at home, at school, or in the physician's presence.

6. Competing Diagnoses. Based on the medical evaluations of our subjects, as well as extensive parent interviews, we can identify in our ADHD group any subjects with a history of other medical diagnoses.

\section{Subject Selection for Data Analysis.}

There were 124 subjects who met the ADHD-Severe criteria and for whom impairment in functioning in at least two settings was present. Of these 124 ADHD-Severe subjects, 58 had ADHD-Combined symptoms, 51 were ADHD-Primarily Inattentive, and 15 were ADHDPrimarily Hyperactive-Impulsive. These subjects also met criteria for impairment in functioning and early onset of symptoms. In our judgment the most stringent test of the impact of ADHD on the dependent variables in question was to compare driving data for ADHD-Severe subjects with driving histories for the remainder of the subjects, which includes those with ADHD Severe symptoms who did not meet the tests of early onset of symptoms or impairment in functioning, ADHD moderate symptoms, ADHD mild symptoms and nosymptoms. The group that did not meet DSMIV severe ADHD criteria will be referred to as the "comparison group" in this report. Of the ADHD-Severe group, driving records were available for 113 (98 females and 15 males). In the comparison group, 350 had driving histories (262 males and 88 females). However, 15 were removed from the final analyses due to incomplete records, bringing the comparison group total to 335. For a second set of analyses we excluded females and those with competing medical diagnoses.

\section{Method}

Driving records by age groups. provided subject's driving histories. records were available from the California Department of Motor Vehicles.
State motor vehicle records The great majority of these 
There were two main searches for driving records. The second search was mainly to update our driving histories for younger subjects. These searches provided a driving history for each subject from age 16 or the age at which he or she first received a drivers license to the subject's current age. The driving records were then summarized according to citations and crashes incurred by age 25, and for those incurred after age 25--an age at which California driving data show a significant drop in citations (Gebers, 1990;1991).

Vehicle registration. In order to have a proxy, although not a perfect one, for amount of vehicle use during the specified age periods, we requested car registration records for our subjects from the California DMV. We coded this information as "owned car" or "not owned car". In analyzing these proxies, the out-of-state subjects were excluded.

Age at which first licensed. The California DMV driving records include the permanent drivers license number which contains a code indicating the year the license was first issued. By subtracting the birth year from the year the license was obtained, we were able to determine the age at which the subject was first licensed. Car registration records and the number of years a subject was licensed to drive provide data by which to compare vehicle driving histories to vehicle availability and use.

\section{Results}

Years of driving and access to vehicles for ADHD-severe subiects and comparison group.

The first step in our analyses was determining any differences between the ADHD and comparison group in the number of years they had been driving. Of the total sample, more of the comparison group were driving by age 16 and had licenses by age 18 . The chi square test was significant at $p<.04$. The data showed that $31 \%$ of the ADHDs had their license by age 16 as compared to $44 \%$ of the comparison group; by age $18,77 \%$ of the ADHDs had licenses compared to $86 \%$ of the Comparison group.

When the analyses included only the male subjects, there were no significant differences in the ages at which driving licenses were obtained, and, therefore, no differences in the number of years that these two groups of male subjects had been driving. Although more of the comparison group males had their licenses by age 16 , the difference leveled off by age 18 when $83 \%$ of the ADHDSevere males as compared to $85 \%$ of the comparison group males had licenses. The remaining $17 \%$ of the male $A D H D-s e v e r e$ group and $15 \%$ of the comparison males who eventually obtained licenses had them by age 25 . 
Chi square results for vehicle registration data showed no differences between ADHD-Severe and comparison subjects with respect to having a vehicle registered in their names. For the total sample, 53\% of the ADHDs and 55\% of the Comparisons had vehicle registrations. When we omitted the female subjects from this analysis, 52\% of the ADHD-severe males compared with 55\% of the comparison group males had vehicles registered to them.

There were differences in the ages at which female subjects obtain their driving licenses, the ADHD-Severe females obtaining licenses at a later age than comparison group females. There were no significant differences, however, between the $A D H D$ and comparison group females in vehicle registrations. We inferred that $A D H D$ females drive cars as adults as frequently as comparison females, but they begin driving at a later age.

Driving histories of violations, crashes, and point-count convictions for ADHD-Severes and comparison group.

We compared the driving records for ADHD-Severes and the comparison group from age of first license through age 25 with respect to the number of point-count convictions, convictions for moving and non-moving violations, crashes, punishments received, and the age of first violation.

The driving histories included all charges, whether they led to conviction or not. For our analyses only convictions are coded. Data were categorized using codes from the state of California Motor Vehicle code book, "H-6 Printouts" (California Department of Motor Vehicles, 1991)

All categories were scored dichotomously as "no offense" or "one or more offenses" and then analyzed using chi square.

Point-Count Convictions. In the point system used by the California Department of Motor Vehicles to classify the seriousness of traffic convictions (for purposes of determining licensing actions), the results showed a marked contrast between the ADHDSevere subjects and the comparison group. ADHD subjects had a significantly higher percentage of 0 -point count and 1 -point count convictions. The same trend, though not statistically significant, was indicated in analysis of 2 -point count convictions. Although the DMV also keeps track of 3 -point count convictions, none of our subjects had this on the driving record.

Moving Violations and Non-Moving Violations. Table 1 shows that the severe ADHD subjects have worse driving records than the comparison group. Half of the convictions for moving violations showed statistically significant differences including sign and signal, speeding, roadway marking, following too closely, and passing. Most of the other convictions showed a trend toward more violations by the ADHD-Severe subjects although the results were 
not statistically significant. For some violation categories, the incidence was too low for the differences to be significant. As current models of driving emphasize ability to pay attention and to concentrate, young adults with inattention and hyperactivityimpulsivity could be expected to show problems in their driving history of traffic convictions.

For non-moving violations the differences were statistically significant in nearly all categories including equipment, licensing, failure to appear in court, failure to pay fines and fees, and ignoring police authority. In all these categories the percentage of violators was higher among the ADHD-Severe subjects.

Crashes. The ADHD-Severe subjects were not significantly different from the comparison group although the trend toward more crashes was evident. Again the incidence for many of the crash categories was low. Data from other studies suggest that risky drivers, i.e. those with a history of prior violations, are more likely to be involved in serious crashes. The ADHD-Severe subjects in this sample may be a continuing risk for crashes as they get older.

Punishments. The driving histories were often striking in the differences between ADHD-Severe subjects and the comparison group in how they coped with a moving violation, and how a moving violation led to attendant problems, and traffic court punishment. For example, one comparison group subject had 5 speeding convictions, but he always paid fines on time, had insurance, and had all equipment and papers in good order. He, therefore, had no related non-moving violations or punishments. In contrast, a pattern for $A D H D$ subjects was that speeding might result in citations not only for speeding, but for no insurance, no smog equipment, and ultimately a license suspension from the DMV for ignoring the citations. Our preliminary analyses, not presented in Table 1 or Table 2, suggest that the ADHD-Severe subjects respond differently to traffic citations. Although the tables show only presence or absence of a conviction or punishment, a perusal of the records indicates that $\mathrm{ADHD}$-Severe subjects appear to have multiple convictions for the same violation while comparison subjects have few repeat occurrences.

Driving Under the Influence. There were no significant differences on "driving while under the influence," or narcoticsrelated driving offenses. The analysis of the rates of alcohol use reported by subjects in our prospective study shows that ADHD subjects do not differ in their use of alcohol from the non-ADHD subjects. This possibly explains why convictions for drunk driving and sentencing by the courts to alcohol programs were comparable for the $\mathrm{ADHD}$-Severes and the comparison group. On the other hand, $A D H D$ subjects are more likely to use cocaine and stimulants, and to be cocaine or stimulant dependent. As the driving records do not indicate whether a conviction is 
attributable to these substances, we can only speculate as to the impact of stimulant dependence on driving, convictions, crashes and punishments.

Age of first driving conviction. There were no significant differences between ADHD-Severes and the comparison group in the age of first driving conviction.

Fatalities. There were two crashes involving "fatalities" for the total sample. Both fatalities occurred with ADHD subjects having severe symptom patterns.

Gender effects on driving histories. In order to take into account possible gender differences in driving histories, we next analyzed the data only for the male subjects. Comparing the results reported in Table 2 for the male subjects with the data reported for the total sample in Table 1 showed only one difference in convictions for moving violations. A larger portion of $A D H D$ males was convicted for "lane placement" violations than the comparison group males.

Stimulant Treatment Histories and Driving Records. The implications of these results suggest that a further examination of the other data available to us would provide information about what factors, in addition to ADHD symptomatology, place a youngster at risk of a poor driving record. A question likely to be raised is whether or not early stimulant medication treatment, the medical treatment of choice for $\mathrm{ADHD}$ subjects, would have had an impact.

As children, $54 \%$ of the ADHD-Severe subjects were treated for 6 months or more with a class of drugs referred to as central nervous system stimulants. The ADHD subjects in this sample most commonly took ritalin although a few were prescribed dexedrine, cylert, deaner or benzedrine. We analyzed the number of moving and non-moving violations, crashes, and punishments for male ADHDSevere subjects who took such medication as children with male $A D H D$-Severe subjects who took no stimulant medication. There were no differences in moving violation convictions, but medicated Severe ADHD males significantly more often were cited with the nonmoving violation of "failure to appear." with respect to "crashes," medicated $A D H D$ severe males were significantly more often involved in a crash and for being at fault for the crash. And finally, there were statistically significant differences in punishments as the medicated $A D H D$-Severe males were more likely to have experienced license suspensions and jail sentences.

These results suggest two possibilities: 1) ADHD-severe subjects who are treated with stimulant medication in childhood are more severely impaired than their non-medicated severe ADHD counterparts; 2) stimulant medication history, alone, does not appear to reduce the likelihood of a poor driving record that includes convictions for non-moving violations, crashes and more dire punishments. 
We have to conclude, finally that ADHD symptoms had a pervasive impact in the lives of children, including their records as adult drivers. 


\section{Implications of the Results}

The results of this study have shown that subjects who are classified according to stringent and severe DSMIV criteria for $\mathrm{ADHD}$ have poorer driving histories when compared to a large group that combines subjects with no ADHD symptoms and those having more moderate $\mathrm{ADHD}$ symptoms. These results are significant because the groups did not differ on the ages at which their licenses were first obtained, access to a vehicle as evidenced by vehicle registration data, and the age of the first traffic conviction. The differences between the two groups are more likely attributable to pervasive inattention and hyperactive-impulsive problems associated with the ADHD diagnosis using our approximations of DSMIV ADHD criteria.

ADHD subjects are known to have concomitant conduct problems, and they smoke more and are more likely to abuse stimulants including cocaine (Lambert, 1988). Although these co-morbid conditions also can contribute significantly to variance in the driving records of the ADHD subject, our planned research did not include further exploration of these as well as other critical factors in driving histories.

The driving histories used in this analysis are especially valuable because we obtained the California records while the DMV was still maintaining lifetime records. Subsequently, the DMV policy was changed and now records are purged periodically. By requesting updates to these driving histories, a new look at how driving habits change over the years is possible.

\section{Planned and Potential Research on Driving Histories and Behavioral Characteristics}

We are proceeding with further study of our adult ADHD and comparison subjects supported by a grant from the National Institute on Drug Abuse (DHHS). In this effort we plan to continue to collect driving histories of our subjects, and to include additional information in our second adult interview to clarify driving patterns.

Second Planned Adult Interview. We will begin interviewing our adult subjects a second time during summer, 1995. We have incorporated questions provided by the NHTSA staff about driving patterns, whether vehicles have been used for going to work, and the amount of current and past driving. Although the results of this interview will not be available for awhile, we will be able subsequently to amplify some of the research results that we have reported.

Results of Search for Missing subjects. The searching service we contacted to provide locations of the 29 subjects for whom we have no driving information was still working on the search at the time of preparation of this final report. 
Analysis of driving histories for females and those with various medical treatment regimens and moderate ADHD symptoms. We used a very restrictive definition of $A D H D$ for the purposes of our preliminary work. We also have not fully explored childhood medical, educational, and psychological interventions, current use of illegal substances or alcohol, or evidence of anti-social behavior or involvement with law enforcement agencies in these analyses. There are many additional and important questions to be addressed with respect to the driving histories of $A D H D$ and compárison subjects. Some of these may be of interest to NHTSA. They are:

1. Additional analysis of the impact of particular ADHD symptom profiles and the severity of the symptoms on driving histories.

2. Examination of the role of drugs and alcohol use/abuse and their impact on driving records.

3. Examination of the role of anti-social personality and criminal histories on driving patterns, convictions, crashes, and point-count convictions.

4. Exploration of the "condition" codes, the flags or stops put on the records by the DMV, as well as the reasons for suspension of drivers licenses by the DMV.

5. Follow-up analysis of driving histories after age 25 to determine whether or not patterns reported in this report continue past the age at which traffic convictions level off for the general population. 


\section{References}

American Psychiatric Association (1968). Diagnostic and Statistical Manual of Mental Disorders (Second Edition). Washington, D.C.: Author.

American Psychiatric Association (1980). Diagnostic and Statistical Manual of Mental Disorders (Third Edition). Washington, D.C.: Author.

American Psychiatric Association (1987). Diagnostic and Statistical Manual of Mental Disorders (Third Edition revised). Washington, D.C.: Author.

American Psychiatric Association (1994). Diagnostic and Statistical Manual of Mental Disorders (Second Edition). Washington, D.C.: Author.

California Department of Motor Vehicles (1991). H-6 Printouts: DMV Departmental Manual. Sacramento, CA: Author.

Gebers, M.A. (1990). Traffic Convictions and Accident Record Facts. Report \#CAL-DMV RSS 127. Sacramento, CA: California Department of Motor Vehicles.

Gebers, M.A. (1991). Traffic Violation Pattern and Age. Report \#CAL DMV RSS 126b. Sacramento, CA: California Department of Motor Vehicles.

Lambert, N.M. (1982). Temperament Profiles of Hyperactive Children. American Journal of Orthopsychiatry, 52, 458-467.

Lambert, N.M. (1988). Adolescent Outcomes for Hyperactive Children: Perspectives on General and Specific Patterns of Childhood Risk for Adolescent Educational, Social, and Mental Health Problems. American Psychologist, 43, 786-799.

Lambert, N. M., Hartsough, C.S., \& Sandoval, J. (1990). The Children's Attention and Adjustment Survey. Circle Pines, MN: American Guidance Service.

Thomas, A., Chess, S., \& Birch, J. G. (1968). Temperament and Behavior Disorders in Children. New York: New York University Press. 


\section{Appendix A}

\section{Research Decision Rules for DSMIV Approximations of the Diagnosis of ADHD}

We used six sets of research decision rules to approximate DSMIV ADHD diagnoses for our community sample of hyperactive (ADHD) and comparison subjects.

1. Evidence of ADHD Problem Behavior. A first step before assigning symptom characteristics to our subjects was to establish a screen for the presence of overall ADHD symptoms. Although such a screening procedure is not required by the DSMIV, we believe that such a procedure was justified. Such a procedure approximates the referral and diagnostic reality in community settings in that it provides a proxy for the overall problems in inattention and hyperactivity/impulsivity that a subject must be experiencing prior to referral for evaluation, at which time DSMIV criteria are then applied. For this purpose we selected those subjects who were classified as pervasive or situational ADHD using ratings from the $A D H D$ scale on the home and school versions of the children's Attention and Adjustment survey (CAAS) (Lambert, sandoval \& Hartsough, 1990). The decision rules for parent or teacher ratings are based on norm reference samples and are presented in the CAAS manual. A subject was classified as "pervasive" if the parent and teacher ratings were both above one standard deviation from the mean on a norm referenced sample and as "situational" if either the parent rating or the teacher rating was in the selection range.

2. Inattentive and Hyperactive-Impulsive DSMIV ADHD Symptoms. We used the CAAS Inattention scale and combined the items from the CAAS Hyperactivity and Impulsivity scales to classify the symptom patterns according to DSMIV standards. The specific rules for the symptom patterns were as follows:

CAAS Inattention--On both home and school versions, 3 or more of the Inattention items rated as "3" (quite a bit) or "4" (very much) or there was an average rating of all Inattention items of 2.5 or higher.

CAAS Hyperactive-Impulsive--On the home version 7 or more items from the combined Hyperactivity and Impulsivity scales rated "3" (quite a bit) or "4" (very much) or there was an average rating of 2.5 or higher. On the school version, 5 or more items on the combined Hyperactivity and Impulsivity scales rated "3" or "4" or there was an average rating on all Hyperactivity and Impulsivity items of 2.5 or higher. 
3. Assignment of Severity Ratings to CAAS DSMIV ADHD Symptom Profiles. We extended the requirements of a DSMIV diagnosis by developing a procedure for assigning a severity rating to the DSMIV symptom profiles. Using the Inattentive and Hyperactive-Impulsive scale scores, we gave the subjects a severity rating as follows:

CAAS DSMIV ADHD - SEVERE. A subject was considered to be pervasively and severely $A D H D$ if the criteria specified above in decision rule number 2 was met in one of the following ways:

* ADHD-Severe Combined Type--A subject satisfied the decision rule on both the Inattention and the Hyperactive-Impulsive scales on both home and school forms.

* ADHD-Severe Predominantly Inattentive Type--A subject met only the Inattention criteria on both home and school forms.

* ADHD-Severe Predominantly Hyperactive-Impulsive Type--A subject met only the Hyperactive-Impulsive criteria on both home and school forms.

CAAS DSMIV ADHD - MODERATE. A subject was considered to be situationally and moderately $A D H D$ if the criteria specified above in decision rule number 2 was met for both Inattention and Hyperactivity/Impulsivity but only on one form (home or school). The moderate categories were:

* ADHD-Moderate Mixed Type. The decision rule was satisfied for Inattention on one form (home or school) and for Hyperactivity/Impulsivity on the other form.

* ADHD-Moderate Combined Type. The decision rule was satisfied for both Inattention and Hyperactivity/Impulsivity on the same form (home or school).

CAAS DSMIV ADHD - MILD. A subject was classified as mild ADHD if only one of the four scales satisfied decision rule Number 2 noted above. The mild categories were:

* ADHD-Mild Inattentive Type. If the decision rule was satisfied for only Inattention on either the home or school forms of the CAAS, the subject was classified as "mild inattentive."

* ADHD-Mild Hyperactive-Impulsive Type. If the decision rule was satisfied for only Hyperactivity/Impulsivity on either the Home or School Forms of the CAAS, the subject was classified as "mild hyperactive-impulsive."

4. Childhood onset of symptoms. Age of onset of the symptoms to meet the DSMIV criteria was determined by one of the following: a) a parent report that the symptoms were first noted 
before age 8 ; b) medical assistance for problems with hyperactivity was sought before age 8 ; or, c) parent rating of the child's temperament on "activity level" or "attention span and persistence" based on analysis (Lambert, 1982) of scales fashioned from Thomas and Chess's New York Longitudinal Study (1968).

5. Impairment in functioning. A subject was considered to satisfy the DSMIV criterion of impairment in function if a parent, teacher, and/or physician judged him or her to be experiencing ADHD symptoms at home, at school, or in the physician's presence.

6. Competing Diagnoses. Medical evaluations of our ADHD subjects, extensive parent interviews, and treatment histories allow us to identify subjects who have other medical problems along with ADHD which might account for their behavior.

Application of these six research decision rules enabled the investigator to use parent and teacher ratings to establish the DSMIV symptom profiles of DSMIV ADHD-Combined, DSMIV ADHD-Primarily Inattentive, and DSMIV ADHD Hyperactive-Impulsive. The DSMIV standards were extended to create a measure of severity through the use of decision rules based on the pervasiveness of the symptoms. If the symptoms were pervasive (both parent and teacher ratings satisfying the decision rules), the symptoms were classified as "severe". If the symptoms were situational (either parent or teacher rating satisfying the decision rule), the symptoms were classified as "moderate" or "mild". Once the severe, moderate, or mild symptom profiles were established, the further DSMIV requirements of onset of symptoms and evidence of impairment were applied. Subjects with other medical diagnoses as well as ADHD can be identified. The determination of the clinical significance of the severe, moderate, and mild categories of DSMIV ADHD symptoms remains to be established by further research. 
Table 1: DRIVING HISTORIES OF ADHD SEVERE AND COMPARISON GROUP

Percentage and number of convictions and punishments on state records from age began driving through age $25 . N=448$.

\begin{tabular}{|c|c|c|c|}
\hline & $\begin{array}{l}\text { ADHD Severe } \\
(\mathrm{N}=113)\end{array}$ & $\begin{array}{l}\text { Comparison } \\
\text { Group } \\
(\mathrm{N}=335)\end{array}$ & $\underset{\left(x^{2)}\right.}{\operatorname{signj}}$ \\
\hline \multicolumn{4}{|c|}{ Total Number of Point Counts ${ }^{1}$} \\
\hline 0 -pt counts & $47.8 \quad(54)$ & $36.1(121)$ & .028 \\
\hline 1 -pt counts & $61.9(70)$ & $47.8 \quad(160)$ & .009 \\
\hline $2-p t$ counts & $23.0 \quad(26)$ & $16.4 \quad(55)$ & NS \\
\hline \multicolumn{4}{|c|}{ Moving violations } \\
\hline Sign, Signal & $36.3 \quad(41)$ & $17.0 \quad(57)$ & .001 \\
\hline Speeding & $52.2 \quad(59)$ & 39.1 (131) & .015 \\
\hline Road markings & $8.0 \quad(9)$ & $1.5(5)$ & .001 \\
\hline Lane Placement & $13.3(15)$ & $9.0 \quad(30)$ & .NS \\
\hline $\begin{array}{l}\text { Following too } \\
\text { close }\end{array}$ & $5.3(6)$ & $.9(3)$ & .004 \\
\hline Passing & $3.5 \quad(4)$ & $.6(2)$ & .02 \\
\hline Right of way & $4.4 \quad(5)$ & $2.1(7)$ & NS \\
\hline $\begin{array}{l}\text { Turning, } \\
\text { stopping }\end{array}$ & $6.2(7)$ & $3.9(13)$ & NS \\
\hline Signalling & $2.7 \quad(3)$ & $1.8(6)$ & NS \\
\hline Drunk driving & $13.3(15)$ & $11.0 \quad(37)$ & NS. \\
\hline Reckless & $9.7(11)$ & $5.4(18)$ & NS \\
\hline Hit and run & $2.7 \quad(3)$ & $1.2(4)$ & NS \\
\hline Other & $13.3(15)$ & $6.3(21)$ & .018 \\
\hline \multicolumn{4}{|c|}{ Non-Moving Violations } \\
\hline Equipment & $50.4 \quad(57)$ & $35.5 \quad(119)$ & .005 \\
\hline Licensing & $33.6 \quad(38)$ & $19.7 \quad(66)$ & .002 \\
\hline $\begin{array}{l}\text { Failure to } \\
\text { appear }\end{array}$ & $45.1(51)$ & $31.3(105)$ & .008 \\
\hline Failure to pay & $8.8(10)$ & $3.9 \quad(13)$ & .04 \\
\hline $\begin{array}{l}\text { Not obey } \\
\text { restrictions }\end{array}$ & - & $.9 \quad(3)$ & NS \\
\hline
\end{tabular}




\begin{tabular}{|c|c|c|c|}
\hline $\begin{array}{l}\text { Police } \\
\text { authority }\end{array}$ & $2.7 \quad(3)$ & $.3(1)$ & .02 \\
\hline \multicolumn{4}{|c|}{ Crashes of all types } \\
\hline Total number & $37.2(42)$ & $31.6 \quad(106)$ & NS \\
\hline At fault & $19.5 \quad(22)$ & $13.7(46)$ & NS \\
\hline $\begin{array}{l}\text { Fault not } \\
\text { reported }\end{array}$ & $17.7(20)$ & $14.3(48)$ & NS \\
\hline Not at fault & $15.0 \quad(17)$ & $9.0 \quad(30)$ & NS \\
\hline $\begin{array}{l}\text { With } \\
\text { Eatalities }\end{array}$ & $1.8(2)$ & -- & .015 \\
\hline With injuries & $14.2 \quad(16)$ & $9.9 \quad(33)$ & NS \\
\hline DUI crashes & $2.7(3)$ & $1.5 \quad(5)$ & NS \\
\hline \multicolumn{4}{|l|}{ Punishments } \\
\hline $\begin{array}{l}\text { License } \\
\text { suspended }\end{array}$ & $45.1(51)$ & $26.9(90)$ & .001 \\
\hline $\begin{array}{l}\text { License } \\
\text { revoked }\end{array}$ & $6.2(7)$ & $2.7(9)$ & NS \\
\hline $\begin{array}{l}\text { License } \\
\text { restricted } \\
\end{array}$ & $5.3(6)$ & 5.7 (19) & NS \\
\hline Other $^{2}$ & $51.3 \quad(58)$ & $46.9 \quad(157)$ & NS \\
\hline Fined & $54.0 \quad(61)$ & $40.0 \quad(134)$ & .01 \\
\hline $\begin{array}{l}\text { Suspended } \\
\text { sentence }\end{array}$ & $10.6(12)$ & $6.6(22)$ & NS \\
\hline Probation & $28.3 \quad(32)$ & $21.5 \quad(72)$ & NS \\
\hline $\begin{array}{l}\text { Alcohol/drug } \\
\text { program }\end{array}$ & $10.6(12)$ & $11.3(38)$ & NS \\
\hline $\mathrm{Jail}$ & $19.5 \quad(22)$ & $14.0 \quad(47)$ & NS \\
\hline
\end{tabular}

1 Point counts are used by the California Department of Motor Vehicles to classify the seriousness of traffic convictions (for purposes of determining licensing actions.)

$0=$ minor

$1=$ serious, e.g. speeding

2 =very serious, e.g. drunk and reckless driving.

2 Forfeiture of bail or marked 'other' in DMV records 


\begin{tabular}{|c|c|c|c|}
\hline \multicolumn{4}{|c|}{$\begin{array}{l}\text { Percentage and number of convictions and punishments on state } \\
\text { driving records from age began driving through age } 25 \\
\text { (restricted sample). }\end{array}$} \\
\hline & $\begin{array}{l}\text { ADHD Severe } \\
\text { males }(n=82)\end{array}$ & $\begin{array}{l}\text { Comparison } \\
\text { Group males } \\
(n=238)\end{array}$ & $\underset{\left(x^{2}\right)}{\operatorname{Signj}}$ \\
\hline \multicolumn{4}{|c|}{ Total Number of Point Counts ${ }^{1}$} \\
\hline $0-p t$ counts & $56.1(46)$ & $40.8 \quad(97)$ & .016 \\
\hline $1-\mathrm{pt}$ counts & $72.0 \quad(59)$ & $53.4 \quad(127)$ & .003 \\
\hline $2-p t$ counts & $25.6 \quad(21)$ & $20.2 \quad(48)$ & NS \\
\hline \multicolumn{4}{|c|}{ Moving Violations } \\
\hline Sign, Signal & $40.2(33)$ & $18.1(43)$ & .001 \\
\hline Speeding & $61.0 \quad(50)$ & $43.3(103)$ & .006 \\
\hline Road markings & $9.8(8)$ & $1.7(4)$ & .001 \\
\hline Lane Placement & $17.1(14)$ & $9.2(22)$ & .053 \\
\hline $\begin{array}{l}\text { Following too } \\
\text { close }\end{array}$ & $6.1(5)$ & $1.3(3)$ & .016 \\
\hline Passing & $4.9 \quad(4)$ & $.8(2)$ & .02 \\
\hline Right of way & $4.9 \quad(4)$ & $2.1(5)$ & NS \\
\hline $\begin{array}{l}\text { Turning, } \\
\text { stopping }\end{array}$ & $4.9 \quad(4)$ & $4.2(10)$ & NS \\
\hline Signalling & $3.7 \quad(3)$ & $2.5 \quad(6)$ & NS \\
\hline Drunk driving & $13.4 \quad(11)$ & $13.4 \quad(32)$ & NS \\
\hline Reckless & $12.2 \quad(10)$ & $7.1 \quad(17)$ & NS \\
\hline Hit and run & $3.7 \quad(3)$ & $1.7 \quad(4)$ & NS \\
\hline Other & $17.1 \quad(14)$ & $7.1 \quad(17)$ & .009 \\
\hline \multicolumn{4}{|c|}{ Non-Moving Violations } \\
\hline Equipment & $57.3(47)$ & $40.8 \quad(97)$ & .009 \\
\hline Licensing & $36.6(30)$ & $23.5(56)$ & .021 \\
\hline $\begin{array}{l}\text { Failure to } \\
\text { appear }\end{array}$ & $50.0(41)$ & $35.7 \quad(85)$ & .022 \\
\hline Failure to pay & 11.0 (9) & $4.6(11)$ & .04 \\
\hline $\begin{array}{l}\text { Not obey } \\
\text { restrictions }\end{array}$ & - & $1.3(3)$ & NS \\
\hline
\end{tabular}




\begin{tabular}{|c|c|c|c|}
\hline $\begin{array}{l}\text { Police } \\
\text { authority }\end{array}$ & $3.7(3)$ & $.4 \quad(1)$ & .023 \\
\hline \multicolumn{4}{|c|}{ Crashes of all types } \\
\hline Total number & $37.8 \quad(31)$ & $31.1 \quad(74)$ & NS \\
\hline At fault & $19.5 \quad(16)$ & $14.7 \quad(35)$ & NS \\
\hline $\begin{array}{l}\text { Fault not } \\
\text { reported }\end{array}$ & $17.1(14)$ & $12.6(30)$ & NS \\
\hline Not at fault & $15.9 \quad(13)$ & $8.0 \quad(19)$ & .04 \\
\hline $\begin{array}{l}\text { With } \\
\text { fatalities }\end{array}$ & $1.2(1)$ & - & NS \\
\hline With injuries & $12.2(10)$ & $10.1(24)$ & NS \\
\hline DUI crashes & $2.4 \quad(2)$ & $2.1(5)$ & NS \\
\hline \multicolumn{4}{|l|}{ Punishments } \\
\hline $\begin{array}{l}\text { License } \\
\text { suspended }\end{array}$ & $51.2 \quad(42)$ & $29.4(70)$ & .001 \\
\hline $\begin{array}{l}\text { License } \\
\text { revoked }\end{array}$ & $7.3(6)$ & $3.4 \quad(8)$ & NS \\
\hline $\begin{array}{l}\text { License } \\
\text { restricted }\end{array}$ & $4.9 \quad(4)$ & $7.1(17)$ & NS \\
\hline Other ${ }^{2}$ & $58.5 \quad(48)$ & $51.3 \quad(122)$ & NS \\
\hline Fined & $62.2(51)$ & $45.0 \quad(107)$ & .007 \\
\hline $\begin{array}{l}\text { Suspended } \\
\text { sentence }\end{array}$ & $12.2(10)$ & $6.7(16)$ & NS \\
\hline Probation & $32.9 \quad(27)$ & $27.3(65)$ & NS \\
\hline $\begin{array}{l}\text { Alcohol/drug } \\
\text { program }\end{array}$ & $9.8(8)$ & $13.9(33)$ & NS \\
\hline Jail & $23.2 \quad(19)$ & $17.2(41)$ & NS \\
\hline
\end{tabular}

* For this table all females were removed from analysis as well as subjects who had received competing medical diagnoses along with ADHD diagnosis. $\mathrm{N}=320$.

1 Point counts are used to classify the seriousness of traffic convictions (For purposes of determining licensing actions). $\quad 0=$ minor 1=serious, e.g. speeding

2 =more serious, e.g. drunk and reckless driving.

2 Forfeiture of bail or marked 'other' in DMV records. 